\title{
Ozone hole deeper than ever
}

\section{- New antarctic data prove chemical cause - Global significance not yet clear}

\section{Washington}

NEw data from the US Antarctic Ozone Project, released in preliminary form last week, will no doubt help to settle the scientific debate over the chemical and meteorological causes of the ozone hole that recurs over the South Pole each austral spring. But whether they will calm the political debate over what should be done is a different matter. In brief, the latest results demonstrate an undoubted chemical cause in the destruction of ozone by atmospheric chlorine, but also point to special climatic conditions as the reason why depletion occurs so severely in the antarctic and so little elsewhere. This leaves room for environmentalists to demand action and for chemical manufacturers to emphasize the lack of imminent global danger.

The project, managed by the National Aeronautics and Space Administration (NASA) with help from other US agencies, foreign countries and the US Chemical Manufacturers Association (CMA), combined airborne and groundbased investigations (see Nature 328, 463; 1987). At a press conference on 30 September, only days after the end of experimental flights, Robert Watson of NASA and Dan Albritton of the National Oceanics and Atmospheric Administration (NOAA) described some of their preliminary scientific findings ahead of publication, in recognition of intense public and political interest.

The concentration of ozone at 70 and $80^{\circ} \mathrm{S}$ was about 15 per cent lower this year than in 1985 , the greatest depletion recorded previously. This is consistent with a suspected trend of increasing ozone loss, modified by a two-year cycle. Two particularly telling details stood out. As ozone destruction proceeded during September, the atmospheric concentration of chlorine monoxide showed a proportional increase; this clearly implicates chlorine chemistry. But the decrease in ozone levels did not proceed smoothly either geographically or with time. On 5 September, a region over the Weddell Sea showed a fall in ozone level of more than 10 per cent in a 24 -hour interval; such an anomaly must, said Watson, reflect local weather conditions, not chemistry. In an official statement, the CMA agreed that the antarctic ozone depletion was a consequence of "unique meteorology and chlorine chemistry".

Instruments aboard a DC-8 flying at $10-$ $12 \mathrm{~km}$ in altitude, and an ER-2 (a modified $\mathrm{U} 2$ spy plane) at up to $18 \mathrm{~km}$ measured concentrations of ozone, chlorine and nitrogen compounds as well as the compositions of stratospheric ice crystals. Taken together, these measurements confirm the peculiar nature of the upper antarctic air, which is not only dehydrated, because water is locked up in ice crystals, but also denitrified (nitrogen oxides are adsorbed onto the ice crystals as nitric acid, and precipitated out of the atmosphere). In normal air, nitrogen oxides are able to lock up chlorine in the form of nitrates, which then cannot destroy ozone. In the denitrified antarctic air, chlorine does other things.

The exact route by which chlorine destroys ozone is still somewhat mysterious. Watson reported that measurements of bromine compounds yielded concentrations of only a few parts per trillion, which inclined him to doubt the importance of a chemical mechanism in which bromine monoxide acts as a catalyst in the destruction of ozone. But Michael McElroy of Harvard University disagrees, saying that even at the reported low concentrations the bromine mechanism would still be more effective than the comparable series of reactions involving chlorine alone. Mike Kurylo, a joint programme manager at NASA, preferred not to favour one mechanism over another, but said that laboratory studies of the rates and yields of the important reactions should, in conjunction with the complete atmospheric data, pin down the chemistry of ozone loss.

Although Watson and Albritton adamantly refused to go beyond their preliminary data, and said it would be unwise to think about global consequences or possible international action before the scientific results are analysed and published, others are not so reticent.

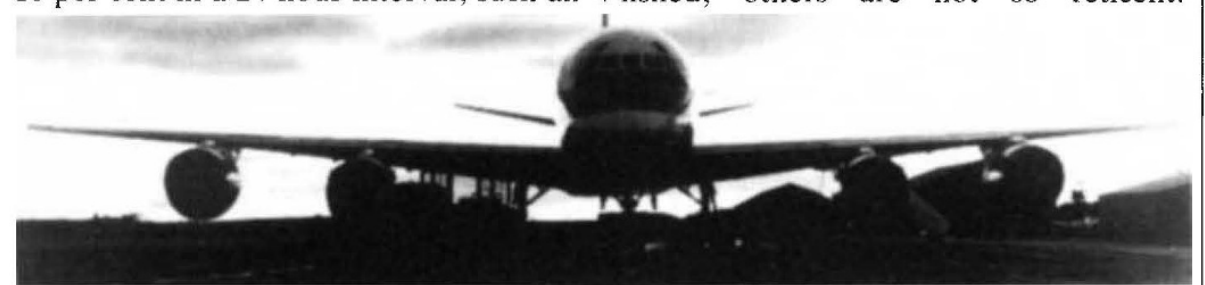

NASA's DC-8-72 flying laboratory.

McElroy, convinced that bromine is critical, is concerned that even a complete cessation of chlorofluorocarbon (CFC) production would leave a reservoir of chlorine in the atmosphere for a century or more, and that bromine emissions must also be halted to prevent continuing erosion of the ozone layer. At present, the two chief sources of atmospheric bromine are methyl bromide, half of which is industrial and half from marine organisms, and halons, chemicals used in nondestructive fire-extinguishers, particularly in the electronics industry. McElroy says that these sources have been increasing at more than 10 per cent per year recently, and may indeed be behind the downwards trend in ozone levels at the south pole.

Irving Mintzer of the World Resources Institute is more optimistic. The newly agreed international protocol on the protection of the ozone layer (see Nature 329, 277 ; 1987) provides for a quadrennial scientific review, as well as for emergency reviews by request of a few of the participating nations. New scientific data will thus be automatically accommodated. And Mintzer sees the participation of the CMA in this venture as recognition that there is now 'market pressure' on industry to develop safer CFCs which do not persist for so long in the atmosphere.

Direct global implications of the ozone hole are hard to fathom. The new data seem to imply that the "chemically perturbed' region corresponds more closely to the area of the antarctic continent than to the area of meteorological oddity, and no scientist is claiming that there is any danger of geographical spreading of the hole. For Mintzer, the significance of the ozone hole is that it has drawn attention to the spectacular way in which human action can alter a piece of the Earth's environment, and at a rate beyond human ability instantly to reverse. David Lindley

\section{GenBank takeover}

Intelligentics Inc., of Mountain View, California, will take over from Bolt Beranek and Newman Inc. as the administrator of GenBank, the governmentsponsored database of genetic sequence information. The Department of Health Services last week announced the fiveyear, \$17.2-million contract. The National Institute of General Medical Sciences is the main funding agency for GenBank, and manager of the project. Intelligenetics will collaborate with Los Alamos National Laboratory to implement the database. The new contractors are hoping to encourage researchers to submit sequence data to GenBank in computer-readable formats, bypassing slower manual data entry. J.P. 